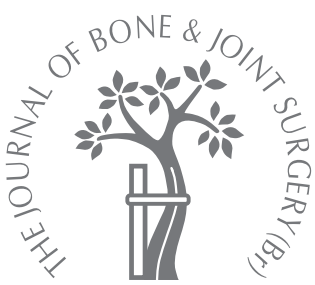

\title{
The impact of national guidelines for the prophylaxis of venous thromboembolism on the complications of arthroplasty of the lower limb
}

S. S. Jameson,

A. Bottle,

A. Malviya,

S. D. Muller,

M. R. Reed

From Northumbria

Healthcare NHS

Trust,

Northumberland, England

- S. S. Jameson, MRCS(Eng), Specialist Registrar

Southern General Hospital,

1345 Govan Road, Glasgow G51 4TF, UK.

A. Bottle, PhD, Lecturer in Medical Statistics

Dr Foster Unit

Imperial Department of Primary

Care and Social Medicine,

Jarvis House, 12 Smithfield

Street, London EC1A 9LA, UK.

A. Malviya, MRCS(Ed),

Specialist Registrar

S. D. Muller, MD,

FRCS(Trauma\&Orth),

Consultant Orthopaedic

Surgeon

M. R. Reed, MD,

FRCS(Trauma\&Orth)

Consultant Orthopaedic

Surgeon

Northumbria Healthcare NHS

Foundation Trust, Woodhorn

Lane, Ashington,

Northumberland NE63 9JJ, UK.

Correspondence should be sent to Mr S.S. Jameson; e-mail:

simonjameson@doctors.org.uk

(C)2010 British Editorial Society of Bone and Joint Surgery doi:10.1302/0301-620X.92B1. $22751 \$ 2.00$

$J$ Bone Joint Surg $[\mathrm{Br}]$ 2010;92-B:123-9.

Received 27 April 2009;

Accepted after revision 10

August 2009

The National Institute for Clinical Excellence (NICE) produces recommendations on appropriate treatment within the National Health Service (NHS) in England and Wales. The NICE guidelines on prophylaxis for venous thromboembolism in orthopaedic surgery recommend that all patients be offered a low molecular weight heparin (LMWH). The linked hospital episode statistics of 219602 patients were examined to determine the rates of complications following lower limb arthroplasty for the 12-month periods prior to and following the publication of these guidelines. These were compared with data from the National Joint Registry (England and Wales) regarding the use of LMWH during the same periods. There was a significant increase in the reported use of LMWH (59.5\% to $67.6 \%$, $p<0.001$ ) following the publication of the guidelines. However, the 90 -day venous thromboembolism events actually increased slightly following total hip replacement (THR, $1.69 \%$ to $1.84 \%, p=0.06$ ) and remained unchanged following total knee replacement (TKR, $1.99 \%$ to $2.04 \%$ ). Return to theatre in the first 30 days for infection did not show significant changes. There was an increase in the number of patients diagnosed with thrombocytopenia, which was significant following THR $(0.11 \%$ to $0.16 \%, p=0.04)$. The recommendations from NICE are based on predicted reductions in venous thromboembolism events, reducing morbidity, mortality and costs to the NHS.

The early results in orthopaedic patients do not support these predictions, but do show an increase in complications.

Prophylaxis for venous thromboembolism after lower limb arthroplasty continues to cause considerable debate..$^{1-3}$ The difference in opinion between the orthopaedic surgeons and physicians is well documented. ${ }^{1,4}$ Historically, the risk of developing a fatal pulmonary embolism was thought to be as high as 3\% following lower limb arthroplasty. ${ }^{5}$ However, using contemporary methods of anaesthesia, surgical techniques and improved rehabilitation, this figure is now less than $0.5 \%{ }^{6}$ Several studies ${ }^{7-9}$ have shown a reduction in both deep-vein thrombosis (DVT) and pulmonary embolism with pharmacological prophylaxis, but there is a need to balance this against the risk of bleeding complications caused by various thromboprophylactic drugs, ${ }^{10}$ prolonged wound drainage ${ }^{11}$ and thrombocytopenia. ${ }^{12}$ In an attempt to prevent venous thromboembolic events, aggressive prophylactic measures could paradoxically increase the risk of harm to patients. Despite rigorous scientific review of the literature on this subject, the various guidelines published by specialist societies and government bodies have failed to reach agreement on the type and duration of prophylaxis. ${ }^{13-17}$
The National Institute for Clinical Excellence (NICE) produces recommendations and guidance on the appropriate treatment and care of patients with specific diseases and conditions within the NHS in England and Wales, based on the best available evidence. ${ }^{18}$ In April 2007, NICE produced guidelines on prophylaxis against venous thromboembolism for patients undergoing surgery, recommending that all orthopaedic in-patients be offered a low molecular weight heparin (LMWH) for the duration of their stay in hospital, whereas high-risk patients, including all patients over 60 years of age, should continue treatment for a further four weeks after discharge. ${ }^{14}$ These guidelines are currently under review, although it is expected that NICE will continue to recommend the extended use of LMWH following lower limb arthroplasty. ${ }^{19}$ Surgeons may only have firsthand experience of very few venous thromboembolic events throughout their career. Therefore, NHS Trusts, keen to avoid the potential litigation following the latter, which comprise $2 \%$ of all claims in the last ten years, ${ }^{20}$ are pressured to follow these national recommendations. 
Table I. ICD-10 and OPCS-4 codes used to identify the patients

\begin{tabular}{|c|c|c|}
\hline Elective procedure & Complication within 90 days & Return to theatre within $\mathbf{3 0}$ days \\
\hline TKR: & 126 & W80.1-3, W80.8-9 \\
\hline W40.1 Cemented & Pulmonary embolus & Open debridement and irrigation of joint \\
\hline \multirow[t]{2}{*}{ W41.1 Uncemented } & $180.1-3,180.8-9$ & \\
\hline & $\begin{array}{l}\text { Phlebitis and thrombophlebitis (all sites } \\
\text { including unspecified }\end{array}$ & $\begin{array}{l}\text { W81 } \\
\text { Other open operations on joint }\end{array}$ \\
\hline \multicolumn{3}{|l|}{ W42.1 Unspecified } \\
\hline THR: & D695 & W90 \\
\hline \multirow[t]{2}{*}{$\begin{array}{l}\text { W37.1 Cemented } \\
\text { W38.1 Uncemented }\end{array}$} & $\begin{array}{l}\text { Secondary thrombocytopenia occurring } \\
\text { with Y442 (anticoagulants) }\end{array}$ & $\begin{array}{l}\text { Puncture of joint } \\
\text { W92 }\end{array}$ \\
\hline & & Other operations on joint \\
\hline W39.1 Unspecified & & S47.2 \\
\hline \multirow[t]{2}{*}{ W93.1 Hybrid, cemented acetabular component } & & Drainage of lesion of skin \\
\hline & & Specifically for TKRs: \\
\hline W94.1 & & W87 \\
\hline Hybrid, cemented femoral component & & $\begin{array}{l}\text { Diagnostic endoscopic examination of } \\
\text { knee joint }\end{array}$ \\
\hline \multirow[t]{5}{*}{ W95.1 Hybrid, unspecified } & & W42.4 \\
\hline & & $\begin{array}{l}\text { Attention to total prosthetic replacement } \\
\text { of knee joint NEC with Y } 221\end{array}$ \\
\hline & & Specifically for THRs: \\
\hline & & W39.4 \\
\hline & & $\begin{array}{l}\text { Attention to total prosthetic replacement } \\
\text { of hip joint NEC with Y } 221\end{array}$ \\
\hline
\end{tabular}

ICD-10, International Statistical Classification of Diseases and Related Health Problems, 10th revision; OPCS-4, Office of Population, Censuses and Surveys Classification of Surgical Operations and Procedures; 4th revision, TKR, total knee replacement; THR, total hip replacement; NEC, not elsewhere classified

NICE estimated that adherence to these guidelines, with $90 \%$ compliance, would result in a reduction in the rate of DVT from $3.3 \%$ to $2.3 \%$ and of pulmonary embolism from $2.3 \%$ to $1.6 \%$ following total hip replacement (THR) over five years in all surgical patients, with an associated reduction in morbidity and mortality and a cost benefit of around $£ 4$ million to the NHS. ${ }^{21}$ However, predicted reductions in venous thromboembolism are based on relatively small clinical trials which attempt to show, statistically, that one treatment is superior to another. The validity of these trials may be compromised by the use of endpoints other than pulmonary embolism, such as symptomatic DVT, which are easier to establish with sufficient power to show differences in treatment, and by financial support from the pharmaceutical industry. ${ }^{20}$

The early effect of the NICE guidelines has yet to be reported. This paper aims to examine their impact on the use of LMWH in patients undergoing arthroplasty of the lower limb in England and Wales, and to analyse the effect on the national rates of complications relating to venous thromboembolic prophylaxis.

\section{Patients and Methods}

We extracted records for patients having elective THRs and total knee replacements (TKRs) from the administrative hospital admissions database (hospital episode statistics), augmented with more recent data from the Secondary Uses
Service. ${ }^{22}$ Hospital episode statistics cover all admissions to NHS hospitals in England and include 14 diagnostic fields, coded using the International Statistical Classification of Diseases and Related Health Problems, ${ }^{23}$ 10th revision (ICD-10 codes), and 12 surgical procedures, coded using the Office of Population, Censuses and Surveys Classification of Surgical Operations and Procedures, 4th revision ${ }^{24}$ (OPCS-4 codes). We linked records belonging to the same patient, defined using a combination of date of birth, gender and postcode, and noted the number of days between the index operation of a primary THR or TKR and any subsequent operation or re-admission. Patients with missing dates of operation were excluded. By employing the appropriate ICD or OPCS codes, complications following primary THRs and TKRs could be identified. Data were obtained on the number of patients returning to theatre within 30 days of the primary procedure for wound complications, excluding a return for reduction of a dislocation, or who were diagnosed with DVT, pulmonary embolism or thrombocytopenia within 90 days even if successfully discharged initially following the primary procedure. The codes are summarised in Table I.

We extracted data on THR or TKR for the 12 months from April 2006 to March 2007 before the introduction of the guidelines, and subsequently from July 2007 to June 2008. In order to allow time for dissemination of these guidelines this second period was from between three and 15 months following publication. These data were compared 
Table II. Data for patients with a total knee replacement recorded in the Hospital Episode Statistics

\begin{tabular}{llll}
\hline & Pre-guideline period & Post-guideline period & p-value \\
\hline Number of joints & 55468 & 60965 & \\
& & & \\
All VTE & & $1244(2.04)$ & 0.60 \\
$\mathrm{DVT}^{\dagger}(\%)$ & $7108(1.99)$ & $54(1.22)$ & 0.43 \\
$\mathrm{PE}^{\ddagger}(\%)$ & $661(1.19)$ & $736(0.88)$ & 0.63 \\
$\mathrm{TCP}^{\S}(\%)$ & $473(0.85)$ & $330(0.54)$ & 0.12 \\
$\mathrm{RTT}^{\S}$ within 30 days $(\%)$ & $59(0.11)$ & & 0.27 \\
\hline
\end{tabular}

* VTE, venous thromboembolism

† DVT, deep-vein thrombosis

‡ PE, pulmonary embolism

$\S \mathrm{TCP}$, thrombocytopenia

I RTT, return-to-theatre

Table III. Details of patients with total hip replacement recorded in the Hospital Episode Statistics

\begin{tabular}{llll}
\hline & Pre-guideline period & Post-guideline period & p-value \\
\hline Number of joints & 49172 & 53997 & \\
& & & \\
All VTE & & & \\
$\mathrm{DVT}^{\dagger}(\%)$ & $892(1.84)$ & 0.06 \\
$\mathrm{PE}^{\ddagger}(\%)$ & $488(0.99)$ & $576(1.07)$ & 0.24 \\
$\mathrm{TCP}^{\S}(\%)$ & $395(0.80)$ & $451(0.84)$ & 0.57 \\
$\mathrm{RTT}^{\uparrow}$ within 30 days $(\%)$ & $55(0.11)$ & $86(0.16)$ & 0.04 \\
\hline
\end{tabular}

* VTE, venous thromboembolism

† DVT, deep-vein thrombosis

¥ PE, pulmonary embolism

$\S \mathrm{TCP}$, thrombocytopenia

I RTT, return-to-theatre

with information requested from the National Joint Registry ${ }^{25}$ regarding the use of LMWH during the same periods for all patients undergoing THR and TKR in England and Wales. As the latter included the Welsh population and patients from the independent sector, the numbers were higher than the hospital episode statistics data, but indicated the general trend in the use of LMWH rather than the absolute numbers. The National Joint Registry does not collect data on the duration of treatment. We have assumed therefore that surgeons using LMWH are compliant with 2007 NICE guidelines during the second 12-month period.

Statistical analysis. Prescribing data from 2005 to 2008 were used to construct a trend curve for the use of LMWH. The rates in the two periods of 12 months were compared using chi-squared tests with the software package SPSS version 15 (Apache Software Foundation, SPSS Inc., Chicago, Illinois).

The Dr Foster Unit at Imperial College has approval to hold patient-identifiable data granted by the Security and Confidentiality Advisory Group, with Section 60 support from the Patient Information Advisory Group and St Mary's local research ethics committee.

\section{Results}

Data from hospital episode statistics were available on 104640 lower limb joint replacements before the intro- duction of the guidelines and on 114962 afterwards. The overall incidence of a venous thromboembolic event following arthroplasty of the lower limb in the English NHS patients rose from $1.85 \%$ (1937 patients) to $1.94 \%$ (2236) over the study period $(\mathrm{p}=0.11)$, and was highest for THR (Tables II and III). The 30-day rate for return-totheatre for infection was unchanged for both THR and TKR. The overall rate of thrombocytopenia secondary to anticoagulants increased significantly from $0.11 \%$ to $0.14 \%(\mathrm{p}=0.05)$, and this was more apparent for THR $(\mathrm{p}=0.04)$ than for TKR $(\mathrm{p}=0.12)$. Data from the National joint registry for the same periods show a significant increase in the use of LMWH for both THRs $(60.7 \%$ to $69.0 \%, \mathrm{p}<0.001)$ and TKRs $(58.4 \%$ to $66.3 \%$, $\mathrm{p}<0.001$ ) (Table IV). These data are summarised in Figures 1 and 2.

Although the use of LMWH increased gradually during 2005/06, the prescribing trend showed an accelerated increase in the percentage of patients receiving LMWH from the second quarter of $2007(62 \%$ for THR to the second quarter of 2008 (73\%, Fig. 3).

\section{Discussion}

Since the introduction of the guidelines, data from the National joint registry have shown a modest but statistically significant increase in the number of patients prescribed 
Table IV. Numbers of patients prescribed low-molecular-weight-heparin (National joint registry data)

\begin{tabular}{llll}
\hline & Pre-guideline period & Post-guideline period & p-value \\
\hline $\operatorname{THR}^{*}(\%)$ & $37408(60.7)$ & $46340(69.0)$ & $<0.001$ \\
$\operatorname{TKR}^{\dagger}(\%)$ & $38010(58.4)$ & $48766(66.3)$ & $<0.001$ \\
Total $(\%)$ & $75418(59.5)$ & $95106(67.6)$ & $<0.001$ \\
\hline
\end{tabular}

* THR, total hip replacement

$\dagger$ TKR, total knee replacement

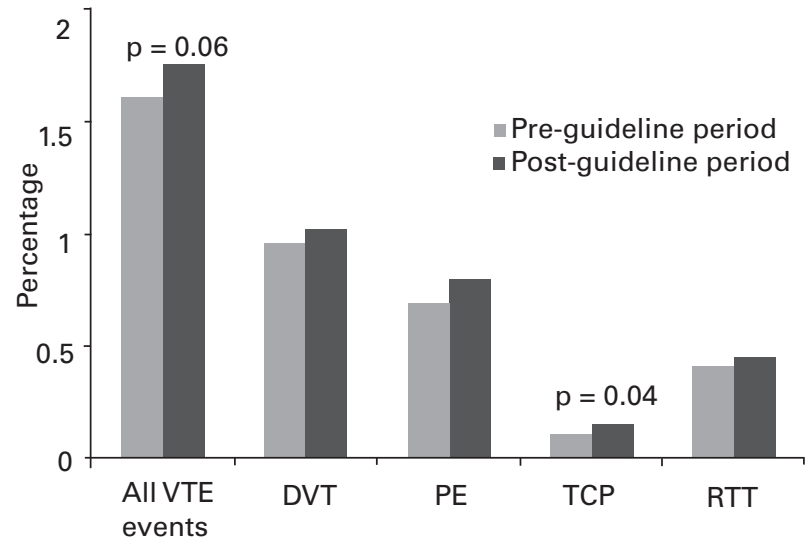

Fig. 1

Bar chart showing the incidence of venous thromboembolism-related complications following total hip replacement (VTE, venous thromboembolism; DVT, deep-vein thrombosis; PE, pulmonary embolism; TCP, thrombocytopenia; RTT, return-to-theatre for infection).

LMWH, with an absolute increase of $8.1 \%$. This appears to have had no beneficial effect on the incidence of venous thromboembolism, with the rate having increased in THR and remaining unchanged in TKR. More worryingly, the rates of thrombocytopenia, a well-recognised side effect of the use of LMWH, have increased significantly after THR. Although the 30-day rate of return-to-theatre for post-operative wound infection has remained almost unchanged, the risk of other wound complications remains unknown.

Data published by the joint registry based on operations linked to hospital episode statistics from April 2003 to September 2007 showed that the incidence of pulmonary embolism at three months following THR was higher in patients given LMWH than in those treated with aspirin, but lower after TKR. ${ }^{6}$ Despite the significant increase in the use of $\mathrm{LMWH}$ presented in this paper there is no apparent fall in the overall rates of pulmonary embolism. ${ }^{6}$ It is worth noting that Cusick and Beverland ${ }^{26}$ found that the overall death rate for their consecutive series of over 4000 lower limb arthroplasties was only $0.31 \%$ when patients were prescribed aspirin only, lower than figures quoted in the National joint registry for any regime. ${ }^{6}$ Parry, Wylde and Blom ${ }^{27}$ reported a $0 \% 30$ - and 90 -day mortality using aspirin alone as chemical thromboprophylaxis in 1549 THRs.

The joint registry group also noted that at three months the rates for pulmonary embolism and mortality were lower for both THR and TKR when mechanical prophy- laxis alone was used rather than aspirin or LMWH, although this was not adjusted for confounding factors. ${ }^{6}$ The NICE guidelines acknowledge the important role of mechanical devices, in reducing the rates of venous thromboembolism recommending their use in all orthopaedic in-patients, together with appropriate anaesthetic techniques, early mobilisation, limb exercises and adequate hydration. ${ }^{18} \mathrm{~A}$ number of small recent studies question the use of any pharmacological agents, suggesting that foot pumps significantly reduce the risk of DVT without the added complications. ${ }^{12,28}$

Adverse events relating to pharmacological prophylaxis are poorly reported, but may be around $2 \% .^{28}$ A large, retrospective analysis of patients with a lower limb arthroplasty showed that the incidence of thrombocytopenia in those prescribed LMWH was significantly higher than in those not receiving this drug. ${ }^{12}$ Patients who developed thrombocytopenia had a greater number of thrombotic events, incurred significantly greater healthcare costs and experienced a longer hospital stay. ${ }^{12}$ Heparin-induced thrombocytopenia and heparin-induced thrombocytopenia with thrombosis are rare immune-mediated adverse drug reactions that occur following exposure to $\mathrm{LMWH}$ and can cause venous thromboembolism, arterial clots and death. Rates of $0.2 \%$ have been reported following administration of LMWH. ${ }^{29,30}$ The mortality rates after heparin-induced thrombocytopenia with thrombosis, for which orthopaedic patients are at a higher risk of developing than medical cardiovascular patients are between $15 \%$ and $30 \%{ }^{31}$ The clinical and economic implications of thrombocytopenia were not assessed by NICE.

NICE estimates that only $60 \%$ of eligible orthopaedic patients receive any form of prophylaxis, as judged by the Department of Health survey of NHS Trusts in 2003. They also anticipated that reducing the rates of DVT would reduce the long-term costs of treating the post-thrombotic limb. The 2007 cost analyses are therefore based on these assumptions. However, according to the fifth Annual Report of the National joint registry, over $99 \%$ of patients undergoing THRs and TKRs during 2007 received some form of prophylaxis, ${ }^{6}$ and so the predicted cost benefits of the widespread use of LMWH in these patients are likely to be inaccurate. Although the benefit of preventing longer term problems with a post-thrombotic limb by avoiding post-operative venographically proven asymptomatic DVT has not yet been clearly established, some (underpowered) 


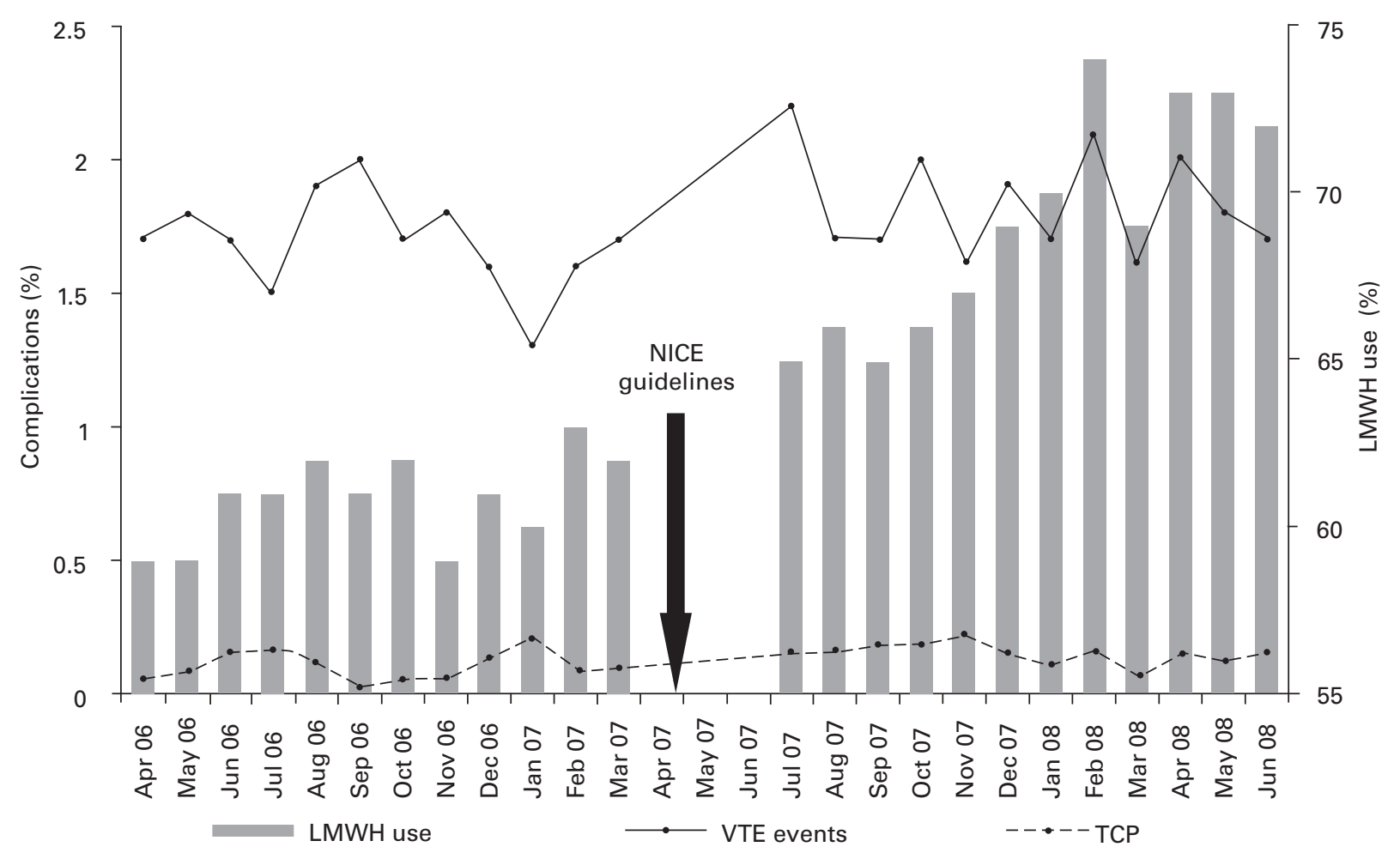

Fig. 2

The use of low-molecular-weight-heparin (LMWH) (all patients recorded on National joint registry in England and Wales) and associated complication rates (English hospital episode statistics data) following total hip replacement over the pre-and post-guideline periods (LMWH, low molecular weight heparin; NJR, national joint registry; HES, hospital episode statistics; THR, total hip replacement; VTE events, venous thromboembolic events (deep venous thrombosis and pulmonary embolus); TCP, thrombocytopenia; NICE, National Institute for clinical excellence).

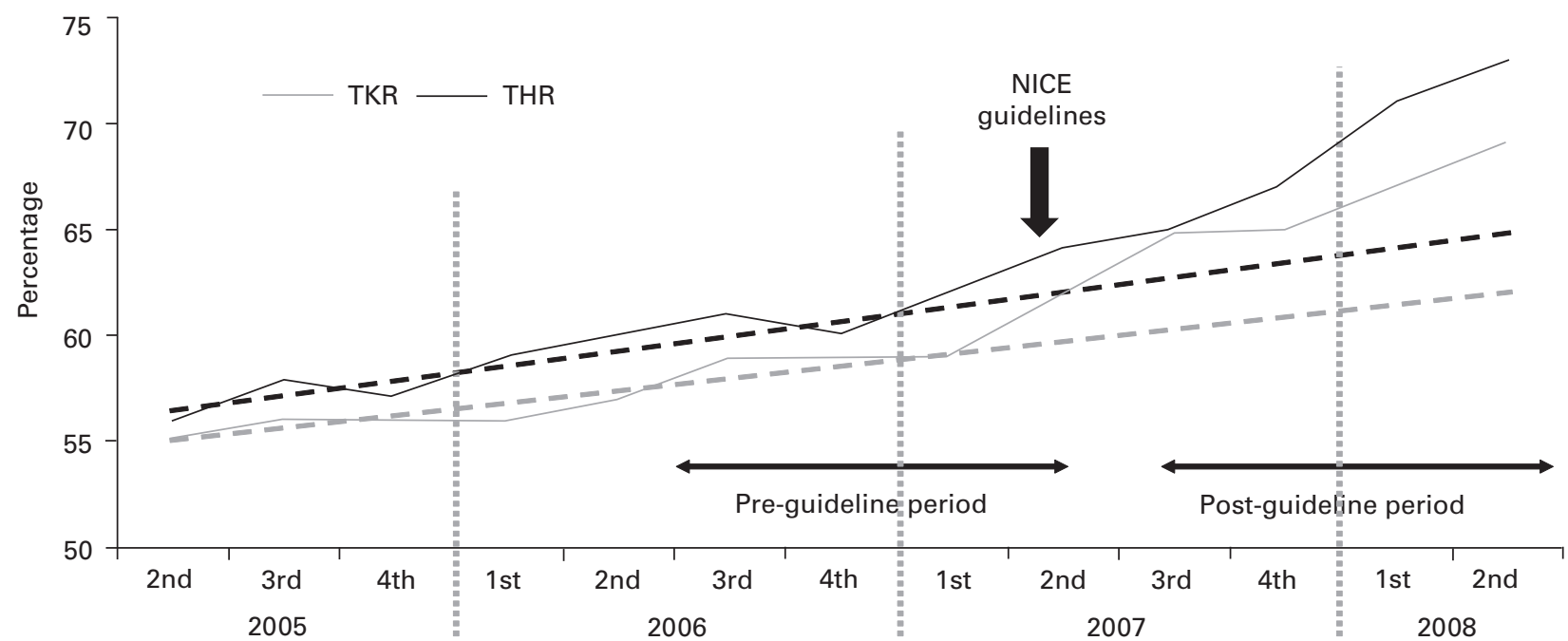

Fig. 3

The quarterly trend of average use of low-molecular-weight-heparin for lower limb arthroplasty (TKR, total knee replacement, THR, total hip replacement; NICE, National Institute for clinical excellence). Dashed trend lines - expected increases based on pre-guideline data.

studies suggest the risk may be no higher than in patients who did not have a DVT. ${ }^{32-34}$

NICE acknowledge that the 'absence of accurate estimates of venous thromboembolic risk in the modern era' make it almost impossible to state the absolute benefits of prophy- laxis. Despite rigorous analyses of the published scientific data, guidelines have failed to reach agreement on the most appropriate prophylaxis. $^{13-17}$ Published randomised controlled trials ${ }^{7-9}$ which appear to be well designed are compromised by insufficient power to detect significant differences in 
the rates of fatal pulmonary embolism, but instead use alternative endpoints that may not accurately reflect the actual risk. Some trials sponsored by industry may have an inherent bias. Whereas NICE, the American College of Chest Physicians and the International Consensus group support the use of LMWH of varying duration, the Scottish Intercollegiate Guidelines Network suggest that aspirin or LMWH may be used. $^{13,14,16,17}$ The American Academy of Orthopaedic Surgeons guidelines, which are based on literature reporting only the reduction of symptomatic pulmonary embolism, failed to identify good evidence for recommending any chemoprophylaxis. ${ }^{15}$ Although this outcome measure may provide more accuracy, it is rarely used in the literature because of the large numbers required to power the statistics sufficiently.

Based on the 2007 NICE guidelines and demographic data from the National joint registry, $75 \%$ of patients undergoing THR should currently receive an extended course of four weeks of LMWH. This will increase to $100 \%$ if the latest NICE consultation guidelines are introduced. ${ }^{19}$ The cost effectiveness of extended treatment with LMWH has both financial and resource implications ${ }^{35}$ and needs to be considered, especially as these new data appear to show no clinical benefit in over 9000 patients, and an increase in the incidence of complications. Daily injections are painful and inconvenient for patients, costly for staff and resources and are not free of complications.

These problems are less of an issue with the newer oral prophylactic drugs. These require no monitoring, do not cause heparin-induced thrombocytopenia and avoid the discomfort, education, safety and resource implications of parenteral agents. In large, double-blinded, randomised controlled trials, oral direct inhibitors of factor Xa were found to significantly reduce venous thromboembolism compared to LMWH after both THR and TKR, with similar rates of bleeding. ${ }^{36-38}$ However, these trials also declare financial support from the manufacturers of such drugs.

NICE are in the process of finalising revised guidelines that are expected to advise extending pharmacological prophylaxis for 28 to 35 days following all THR, and for ten to 14 days after TKR. ${ }^{19}$ They may recommend the use of oral anticoagulants as an alternative.

Data from hospital episode statistics have been shown to have inaccuracies in the past, ${ }^{39}$ but this current in-patient dataset represents the most accurate yet. ${ }^{40}$ Given the maturity of the system of data collection, increased rates of complications seen over the study period are unlikely to be attributable purely to improvements in coding. As these data are collected routinely at a local level by coding staff and then collated nationally, the investigating team for this study and individual clinicians are unable to bias the results. Therefore it is likely that the increased complication rates seen in this dataset have been correctly identified.

The increase in the prescription of LMWH, albeit significantly higher since the introduction of the guidelines has not been as dramatic as expected, which may be the result of the relatively short period between publication and the start of the second period of data collection. Figure 3 shows that the prescribing curve for LMWH steepens from the second quarter of 2007 compared to the preceeding two years. Some Trusts may have anticipated these recommendations and implemented changes early. However, funding issues in other Trusts may have stifled this process. Also, users of LMWH are more likely to extend the duration of therapy since publication of the guidelines. It seems clear that, despite the additional expenditure and use of $\mathrm{LMWH}$, the expected reduction in the rates of complication has not occurred.

Unfortunately, the data collection and coding of patients who are diagnosed with DVT as outpatients are less reliable, and the figures presented here may underestimate the incidence of DVT at 90 days. However, this is consistent across both these study periods and the National joint registry analyses. The joint registry and hospital episode statistics data were not linked in this analysis. We were unable to show the rates of fatal pulmonary embolism in our assessment, but it is generally assumed that the overall rate of pulmonary embolism mirrors the fatalities from it. ${ }^{16,29}$

The obvious flaws of an observational study are well known. We are unable to provide data on the duration of treatment. However, previous studies have shown that two-thirds of venous thromboembolic events following THR occur prior to discharge. Although we acknowledge that some patients who received LMWH after publication of the guidelines may not have received an extended duration of treatment, a fall in venous thromboembolism should still be anticipated if LMWH has an effect, and of the $60 \%$ of clinicians prescribing LMWH prior to April 2007, many may have changed to the extended duration.

This study describes the impact of the guidelines on orthopaedic practice at a national level, and provides independent data for a large population. Previous power calculations have suggested that a study size of 20000 is required to show a significant change in the rates of clinical DVT and pulmonary embolism. ${ }^{41}$ Because an absolute increase in the prescription of LMWH of $8.1 \%$ was seen in the joint registry, we can assume that 9312 more patients recorded in the hospital episode statistics data were prescribed LMWH in the period after publication of the guidelines ([60 965 TKRs +53 997 THRs $] \times 0.081$ ). These data are therefore of the correct order of magnitude to have sufficient power to demonstrate an effect of LMWH on these clinical endpoints irrespective of the duration of treatment. Also, Prentice ${ }^{42}$ has noted that haemorrhage, both at the surgical site and elsewhere, must be known for a true balance of risk and benefit. We have provided data on return-to-theatre rates for infection and anticoagulant-induced thrombocytopenia, which were previously unavailable on this scale.

The aim of the NICE guidelines was to reduce the quoted figure of 25000 deaths per year in England as a result of venous thromboembolism acquired in hospital. ${ }^{21}$ Approximately 500 of these deaths ( $2 \%)$ followed THR or TKR, as recorded as deaths from a pulmonary embolism in the National joint registry. ${ }^{6}$ About one-third of orthopaedic surgeons in England and Wales continue to practise outside the NICE guidelines, with similar figures reported else- 
where for other population groups. ${ }^{35}$ It is now over two years since publication of the guidelines, and yet despite national recommendations there has been only a limited increase in the use of LMWH. We have demonstrated that, despite this increase, the incidence of complications of VTE in over 100000 patients has not decreased, but the incidence and the associated costs of treating thrombocytopenia have increased. Based on these results, the predicted saving of $£ 4$ million for the NHS is unlikely to be achieved.

\section{Supplementary material}

$\ddot{e}$ A further opinion by Professor R. Atkins is available with the electronic version of this article on our website at www.jbjs.org.uk

A. Bottle and the Dr Foster Unit are principally funded by Dr Foster Intelligence a private healthcare information company, through a research grant for the Unit No benefits in any form have been received or will be received from a commercial party related directly or indirectly to the subject of this article.

\section{References}

1. Haas SB, Barrack RL, Westrich G, Lachiewicz PF. Venous thromboembolic disease after total hip and knee arthroplasty. J Bone Joint Surg [Am]2008;90-A:2764-80.

2. Pellegrini VD Jr, Donaldson CT, Farber DC, Lehman EB, Evarts CM. Prevention of readmission for venous thromboembolism after total knee arthroplasty. Clin Orthop 2006;452:21-7.

3. Parvizi J, Azzam K, Rothman RH. Deep venous thrombosis prophylaxis for total joint arthroplasty: American Academy of Orthopaedic Surgeons guidelines. J Arthroplasty 2008;23(Suppl):2-5

4. Eikelboom JW, Karthikeyan G, Fagel N, Hirsh J. American Association of Orthopaedic Surgeons and American College of Chest Physicians guidelines for venous thromboembolism prevention in hip and knee arthroplasty differ: what are the implications for clinicians and patients? Chest 2009;135:513-20

5. Salvati EA, Pellegrini NE, Sharrock NE, et al. Recent advances in venous thromboem bolic prophylaxis during and after total hip replacement. J Bone Joint Surg [Am] 2000;82A:252-70.

6. No authors listed. National Joint Registry. 5th Annual Report. http://www.njircentre.org.uk/NjrCentre/Link-

Click.aspx?fileticket=Da4\%2b2sUVa\%2f1\%3d\&tabid=86\&mid=523 (date last accessed 23 April 2009).

7. Bergqvist D, Benoni G, Bjorgell 0, et al. Low-molecular-weight heparin (enoxaparin) as prophylaxis against venous thromboembolism after total hip replacement. $N$ Engl J Med 1996:335:696-700

8. Haas S, Breyer HG, Bacher HP, et al. Prevention of major venous thromboembolism following total hip or knee replacement: a randomized comparison of low-molecular-weight heparin with unfractionated heparin (ECHOS trial) Int Angiol 2006;25:335-42.

9. Fitzgerald RH Jr, Spiro TE, Trowbridge AA, et al. Prevention of venous thromboembolism disease following primary total knee arthroplasty: a randomized, multi-center, openlabel, parallel-group comparison of enoxaparin and warfarin. J Bone Joint Surg [Am] 2002;84-A:879-80

10. Streiff MB, Haut ER. The CMS ruling on venous thromboembolism after total knee or hip arthroplasty: weighing risks and benefits. JAMA 2009;301:1063-5.

11. Patel VP, Walsh M, Sengal B, et al. Factors associated with prolonged wound drainage after primary total hip and knee arthroplasty. J Bone Joint Surg [Am] 2007;89-A:33-8.

12. Pitto RP, Hamer H, Heiss-Dunlop W, Kuehle J. Mechanical prophylaxis of deep-vein thrombosis after total hip replacement: a randomised clinical trial. J Bone Joint Surg [Br] 2004;86-A:639-42.

13. Geerts WH, Bergqvist D, Pineo GF, et al. Prevention of venous thromboembolism: American College of Chest Physicians evidence-based clinical practice guidelines (8th Edition). Chest 2008; 133(Suppl):381-453

14. No authors listed. National Institute for Clinical Excellence. Venous thromboembolism: reducing the risk of venous thromboembolism (deep vein thrombosis and pulmonary embolism) in inpatients undergoing surgery. http://www.nice.org.uk/Guidance/ CG46/NiceGuidance/pdf/English, April 2007. www.aaos.org/research/guidelines/ PE-guideline.pdf (date last accessed 6 September 2009).
15. American Academy of Orthopaedic Surgeons. Clinical guidelines on prevention of symptomatic pulmonary embolism in patients undergoing total hip or knee arthroplasty 2007. www.aaos.org/research/guidelines/PE guideline.pdf (date last accessed 6 September 2009).

16. No authors listed. Scottish Intercollegiate Guidelines Network (SIGN). http:// www.sign.ac.uk (date last accessed 23 April 2009).

17. Nicolaides AN, Fareed J, Kakkar AK, et al. Prevention and treatment of venous thromboembolism International Consensus Statement (guidelines according to scientific evidence). Int Angiol 2006;25:101-61.

18. No authors listed. National Institute for Clinical Excellence. http://www.nice.org.uk (date last accessed 23 April 2009).

19. No authors listed. National Institute for Clinical Excellence. Venous thromboembolism: reducing the risk: full guideline for consultation. http://www.nice.org.uk/guidance/index.jsp?action-download\&0=43395 (date last accessed 23 April 2009).

20. Warwick D, Dahl OE, Fisher WD. Orthopaedic thromboprophylaxis: limitations of current guidelines. J Bone Joint Surg [Br] 2008;90-B:127-32.

21. No authors listed. National Institute for Clinical Excellence. Venous thromboembolism: costing report. http://www.nice.org.uk/nicemedia/odf/CG046CostingReport.pdf (date last accessed 23 April 2009).

22. No authors listed. Connecting for Health. http://www.connectingforhealth.nhs.uk/ systemsandservices/sus (date last accessed 23 April 2009).

23. No authors listed. World health organisation. ICD-I0. www.who.int/classifications/ icd/en (date last accessed 19 November 2009).

24. No authors listed. Connecting for health. OPCS 4. www.connectingforhealth.nhs.uk/systemsandservices/data/clinicalcoding/codingstandards/opcs4 (date last accessed 19 November 2009).

25. No authors listed. National Joint Registry. http://www.njrcentre.org.uk (date last accessed 23 April 2009).

26. Cusick LA, Beverland DE. The incidence of fatal pulmonary embolus after primary hip and knee replacement in a consecutive series of 4253 patients. J Bone Joint Surg [Br] 2009;91:645-8

27. Parry M, Wylde V, Blom AW. Ninety-day mortality rate after elective total hip replacement: 1549 patients using aspirin as a thromboprophylactic agent. J Bone Joint Surg [Br] 2008;90-B:306-7.

28. Daniel J, Pradhan A, Pradhan C, et al. Multimodal thromboprophylaxis following primary hip arthroplasty: the role of adjuvant intermittent pneumatic calf compression. J Bone Joint Surg [Br] 2008;90-B:562-9.

29. Gillespie W, Murray D, Gregg PJ, Warwick D. Risks and benefits of prophylaxis against venous thromboembolism in orthopaedic surgery. J Bone Joint Surg $[\mathrm{Br}]$ 2000;82-B:475-9.

30. Happe LE, Farrelly EM, Stanford RH, Sarnes MW. Cost and occurrence of thrombocytopenia in patients receiving venous thromboembolism prophylaxis following major orthopaedic surgeries. J Thromb Thrombolysis 2008;26:125-31.

31. Baroletti S, Piovella C, Fanikos J, et al. Heparin-induced thrombocytopenia (HIT): clinical and economic outcomes. Thromb Haemost 2008;100:1130-5.

32. Baglin TP. Heparin induced thrombocytopenia thrombosis (HIT/T) syndrome: diagnosis and treatment. J Clin Pathol 2001;54:272-4.

33. Muller SD, Khaw FM, Morris R, Crozier AE, Gregg PJ. Ulceration of the lower leg after total knee replacement: a five-year review. J Bone Joint Surg [Br] 2001;83-A:1116-18.

34. Cordell-Smith JA, Williams SC, Harper WM, Gregg PJ. Lower limb arthroplasty complicated by deep venous thrombosis: prevalence and subjective outcome. J Bone Joint Surg [Br] 2004;86-B:99-101.

35. Ginsberg JS, Turkstra F, Buller HR, et al. Post-thrombotic syndrome after hip or knee arthroplasty: a cross-sectional study. Arch Intern Med 2000;160:669-72.

36. Friedman RJ, Gallus AS, Cushner FD, Fitzgerald G, Anderson FA Jr. Physician compliance with guidelines for deep-vein thrombosis prevention in total hip and knee arthroplasty. Curr Med Res Opin 2008;24:87-97.

37. Lassen MR, Ageno W, Borris LC, et al. Rivaroxaban versus enoxaparin for thromboprophylaxis after total knee arthroplasty. N Eng/ J Med 2008;358:2776-86.

38. Eriksson BI, Kakkar AK, Turpie AG, et al. Oral rivaroxaban for the prevention of symptomatic venous thromboembolism after elective hip and knee replacement. J Bone Joint Surg [Br] 2009;9-1-B:636-44

39. Eriksson BI, Borris LC, Friedman RJ, et al. Rivaroxaban versus enoxaparin for thromboprophylaxis after hip arthroplasty. N Engl J Med 2008;358:2765-75.

40. Westaby S, Archer N, Manning N, et al. Comparison of hospital episode statistical and central cardiac audit database in public reporting of congenital heart surgery mortality. BMJ 2007;335:759

41. Hitos K, Fletcher JP. Venous thromboembolism following primary total hip arthroplasty. Int Angiol 2009;28:215-21.

42. Prentice CRM. Prophylaxis against DVT following hip replacement: which treatment for which patient? J Bone Joint Surg [Br] 2000;82-B:483-5. 